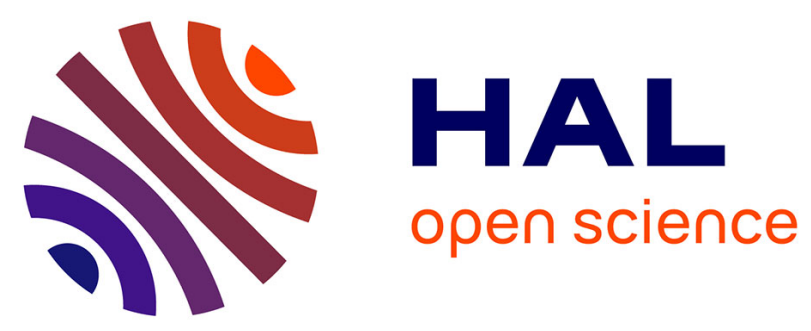

\title{
Local imipenem activity against decreases in vivo in the presence of siliconized latex
}

\author{
C. Pichardo, M. C. Conejo, F. Docobo-Pérez, C. Velasco, R. López-Rojas, I.
} García, M. E. Pachón-Ibáñez, J. M. Rodríguez, J. Pachón, A. Pascual

\section{To cite this version:}

C. Pichardo, M. C. Conejo, F. Docobo-Pérez, C. Velasco, R. López-Rojas, et al.. Local imipenem activity against decreases in vivo in the presence of siliconized latex. European Journal of Clinical Microbiology and Infectious Diseases, 2010, 30 (2), pp.289-291. 10.1007/s10096-010-1084-y . hal00630414

\section{HAL Id: hal-00630414 \\ https://hal.science/hal-00630414}

Submitted on 10 Oct 2011

HAL is a multi-disciplinary open access archive for the deposit and dissemination of scientific research documents, whether they are published or not. The documents may come from teaching and research institutions in France or abroad, or from public or private research centers.
L'archive ouverte pluridisciplinaire HAL, est destinée au dépôt et à la diffusion de documents scientifiques de niveau recherche, publiés ou non, émanant des établissements d'enseignement et de recherche français ou étrangers, des laboratoires publics ou privés. 
Diseases

Editorial Manager(tm) for European Journal of Clinical Microbiology \& Infectious

Manuscript Draft

Manuscript Number: EJCMID-D-10-00315R2

Title: Local imipenem activity against Pseudomonas aeruginosa decreases in vivo in the presence of siliconized latex.

Article Type: Brief Report

Keywords: Pseudomonas aeruginosa; zinc; latex; experimental foreign body peritonitis model

Corresponding Author: Dr. Cristina Pichardo, Ph.D.

Corresponding Author's Institution:

First Author: Cristina Pichardo, Ph.D.

Order of Authors: Cristina Pichardo, Ph.D.; MCarmen Conejo; Fernando Docobo-Pérez; Carmen Velasco; Rafael López-Rojas; Isabel García; MEugenia Pachón-Ibáñez; J Manuel Rodríguez; Jerónimo Pachón; Álvaro Pascual

Abstract: Zinc eluted from siliconized latex (SL) increases resistance of Pseudomonas aeruginosa to imipenem in vitro. A foreign body peritonitis model was used to evaluate the activity of imipenem using SL or silicone (S) implants. No differences were observed in mortality, positive blood cultures and tissue bacterial counts between SL and S implants. Implant-associated counts, however, were significantly higher in the SL group. It is concluded that SL decreases the activity of imipenem against P. aeruginosa. 
September 22, 2010

Dr. Alex van Belkum

Editor-in-Chief

European Journal of Clinical Microbiology \& Infectious Diseases

Dear Dr. van Belkum,

Please find enclosed the revised version of the manuscript entitled "Local imipenem activity against Pseudomonas aeruginosa decreases in vivo in the presence of siliconized latex" (Ref.: Ms. No. EJCMID-D-10-00315R1). Following your suggestion we have introduced the changes suggested by reviewer \# 1 . These changes are detailed below:

\section{Reviewer \#1: The revised manuscript addresses the issue raised.}

One clarification should be made in the text as well. The authors should clearly state that the experiment was repeated 3 times with 5 animal per group and not just state that 15 animals were studied.

As suggested by reviewer 1, the following paragraph has been added in the revised manuscript in order to clarify it (Pg 4 line 74$)$.

"The in vivo studies were performed three times using 5 mice per assay for a total of 15 mice per group. Also, the experiments were performed on different days, thus avoiding bias that might vary from one day to another. The size of the groups $(n=15)$ are sufficient for detecting a statistical difference, between the groups, of $1.5 \mathrm{cfu} / \mathrm{g}$, with an alpha error of 0.05 and a beta error of 0.20 . Animals were randomized into four groups on the basis of implant type and the treatment received for $72 \mathrm{~h}$ "

\section{Pg 3 line 35-the author should state that this was In-Vitro data (ref 1)}

Following the suggestion of reviewer 1, this comment has been included in the new version of the manuscript (Pg 3 line 33).

"In the in vitro study, we have observed that eluates from SL urinary catheters decrease the activity of carbapenems against $P$. aeruginosa [1]"

Yours sincerely,

Cristina Pichardo 


\section{TITLE:}

2 Local imipenem activity against Pseudomonas aeruginosa decreases in vivo in the presence of siliconized

3 latex.

4

5 Pichardo $\mathrm{C}^{1}$, Conejo $\mathrm{MC}^{2}$, Docobo-Pérez $\mathrm{F}^{1}$, Velasco $\mathrm{C}^{2}$, López-Rojas $\mathrm{R}^{1}$, García $\mathrm{I}^{2}$, Pachón-Ibáñez $6 \mathrm{ME}^{1}$, Rodríguez $\mathrm{JM}^{2}$, Pachón $\mathrm{J}^{1}$, Pascual $\mathrm{A}^{2}$.

\section{FROM:}

$9{ }^{1}$ Infectious Diseases Service, Instituto de Biomedicina de Sevilla, Hospital Universitario Virgen del 10 Rocío/CSIC/Universidad de Sevilla. ${ }^{2}$ Department of Microbiology. School of Medicine. Sevilla. Spain. 11

12 Corresponding author: Cristina Pichardo. Instituto de Biomedicina de Sevilla, Hospital Universitario 13 Virgen del Rocío/CSIC/Universidad de Sevilla.

14 Avda. Manuel Siurot s/n, 41013 Seville, Spain.

15 Phone: +34 95501 3652. Fax: +34 955012377.

16 E-mail: cristina.pichardo.exts@juntadeandalucia.es.

18 RUNNING TITLE: Experimental foreign body peritonitis by $P$. aeruginosa

20 KEY WORDS: Pseudomonas aeruginosa, zinc, latex, experimental foreign body peritonitis model. 


\section{ABSTRACT}

24

25 Zinc eluted from siliconized latex (SL) increases resistance of Pseudomonas aeruginosa to imipenem in 26 vitro. A foreign body peritonitis model was used to evaluate the activity of imipenem using SL or silicone 27 (S) implants. No differences were observed in mortality, positive blood cultures and tissue bacterial 28 counts between SL and S implants. Implant-associated counts, however, were significantly higher in the 29 SL group. It is concluded that SL decreases the activity of imipenem against $P$. aeruginosa. 30 
Pseudomonas aeruginosa is a significant cause of urinary tract infections in patients with urinary

34 catheters. Siliconized latex (SL) is the biomaterial most commonly used to make urinary catheters. In the 35 in vitro study, we have observed that eluates from SL urinary catheters decrease the activity of 36 carbapenems against $P$. aeruginosa [1]. The effect is related to changes in the outer membrane protein 37 profile of P. aeruginosa in the presence of zinc eluted from SL [2]. This reversible phenomenon is mediated by the expression of the heavy metal efflux pump CzcCBA in the presence of high zinc concentrations [3,4]. Since the clinical relevance of this phenomenon is unknown, an experimental model of foreign body infection in mice was used to evaluate the treatment of $P$. aeruginosa infection with imipenem in the presence of SL versus silicone (S) implants.

\section{$44 \quad$ Material and methods}

Bacterial strain.

Antimicrobial agents and Catheter.

Imipenem (laboratory standard powder) and Imipenem plus cilastatin was obtained from Merck 54 and Sharp and Dohme (Madrid, Spain).

$\mathrm{S}$ catheters (10 argyle all silicone Foley catheter 8FR/CH; Sherwood Medical, Tullamore, 56 Ireland) and SL catheters (two-way pediatric silicone-coated latex Foley catheter 8FR/CH; Kendall Co., 57 Kangar, Malaysia) with an internal diameter of $0.8 \mathrm{~mm}$ and an external diameter of $2.8 \mathrm{~mm}$ were cut into 58 segments of $10 \mathrm{~mm}$ and used as implants. 
Experimental animal model. determined. after insertion of the implant. survival rate was $100 \%$.

Immunocompetent pathogen free C57BL/6 female mice weighing 14 to $16 \mathrm{~g}$ were use in our model. Animals were housed in regulation cages and given free access to food and water. The studies were approved by the Ethics Committee of the University Hospitals Virgen del Rocío (Seville, Spain). Plasma levels of imipenem were determined after administration of a single intramuscular (im) dose of 60 $\mathrm{mg} / \mathrm{kg}$. Total plasmatic drug concentrations were measured using the bioassay method (Micrococcus luteus ATCC 9341 as the indicator strain), pharmacokinetics and pharmacodinamics parameters were

The murine model of foreign-body peritonitis described by Espersen et al. was used [3]. Experimental infection was produced by intraperitoneal injection with $1 \mathrm{ml}$ of bacterial suspension in saline $\left(10^{6}-10^{7} \mathrm{CFU} / \mathrm{ml}\right)$ in the lateral abdominal wall opposite of the operation wound fifteen minutes

Preliminary experiments were carried out to evaluate survival of animals after placement of catheter compared to animals that underwent the operation without catheter placement. In both groups the

The in vivo studies were performed three times using 5 mice per assay for a total of 15 mice per group. Also, the experiments were performed on different days, thus avoiding bias that might vary from one day to another. The size of the groups $(n=15)$ are sufficient for detecting a statistical difference, between the groups, of $1.5 \mathrm{cfu} / \mathrm{g}$, with an alpha error of 0.05 and a beta error of 0.20 . Animals were randomized into four groups on the basis of implant type and the treatment received for $72 \mathrm{~h}$ : SL implant not treated (control SL); S implant not treated (control S); SL implant imipenem treated (imipenem SL), $240 \mathrm{mg} / \mathrm{kg} / \mathrm{d}$, (four doses of $60 \mathrm{mg} / \mathrm{kg}$ ) im; and S implant imipenem treated (imipenem S), $240 \mathrm{mg} / \mathrm{kg} / \mathrm{d}$, (four doses of $60 \mathrm{mg} / \mathrm{kg}$ ) im; the dosing regimen of imipenem chosen resulted in a $\Delta \mathrm{T} / \mathrm{MIC}$ for the PAO1 strain which was $48.8 \%$ of the dosing interval. The animals were observed for $72 \mathrm{~h}$ for mortality, and surviving mice were killed $4 \mathrm{~h}$ after the last dose. All mice were analyzed immediately after death. Once the animals were dead, the thorax and abdomen were opened. Blood was obtained by cardiac puncture and qualitative culture was carried out by inoculating sterile tubes with $2 \mathrm{~mL}$ of MHB and incubating for 
$24 \mathrm{~h}$ at $37^{\circ} \mathrm{C}$. Then, $100 \mu 1$ of each sample was plated on Columbia sheep-blood agar and incubated for 24

$89 \mathrm{~h}$ at $37^{\circ} \mathrm{C}$. The results of the blood cultures were expressed as positive or negative. On the other hand, the

90 peritoneal cavity was inspected, and the foreign body (catheter), the liver and the spleen, were aseptically

91 removed for culture. One $\mathrm{ml}$ of sterile saline was slowly flushed through the catheter to remove blood and

92 non-adherent organisms. Later, the catheter was placed in $1 \mathrm{ml}$ of saline in a 2 -ml tube. The tube was

93 sonicated for $8 \mathrm{~min}$ at $40-60 \mathrm{kHz}$ (Ultrasons 513 water bath sonicator [P Selecta]) and quantitative

94 cultures of the saline were performed (catheter washings). The liver and the spleen were extracted and

95 separated onto a sterile Petri plate and weighed. The tissues were processed for quantitative culture, after

96 being homogenized in $2 \mathrm{ml}$ of sterile saline solution (Stomacher 80 Tekmar CO., Cincinnati, OH, USA).

97 After ten-fold dilution, aliquots of $100 \mu \mathrm{L}$ were plated onto Columbia sheep-blood agar and incubated for

$9824 \mathrm{~h}$ at $37^{\circ} \mathrm{C}$; results were expressed as the mean $\pm \mathrm{SD}$ of the $\log \mathrm{CFU} / \mathrm{g}$ of the tissues and the mean $\pm \mathrm{SD}$

99 of the $\log \mathrm{CFU} / \mathrm{ml}$ of catheter washings. Sterile cultures were considered to have $\leq 1 \log \mathrm{CFU} / \mathrm{ml}$ of

100 catheter washings. Statistical comparisons between groups were made using the variance analysis

101 (ANOVA) and multiple comparisons post-hoc tests (Dunnett or Tukey-Kramer). To compare the number

102 of survivors and the number of sterile tissues, the Fisher exact test was used. A value of $p<0.05$ was

103 considered significant.

104

105 Results and Discussion

106

107 Pharmacokinetics studies.

108

109

The intraday and interday variation of the assays were $2.62 \% \pm 2.44 \%$ and $3.22 \% \pm 1.91 \%$; the 110 linearity $\left(\mathrm{r}^{2}\right)$ of the assay $0.91 \pm 0.02$ and the lower limit of detection was $0.01 \mu \mathrm{g} / \mathrm{ml}$. The maximum 111 plasma concentration $\left(\mathrm{C}_{\max }\right)$ of imipenem and the terminal half-life $\left(\mathrm{t}_{1 / 2}\right)$, were $30.56 \mu \mathrm{g} / \mathrm{ml}$ and $0.5 \mathrm{~h}$, 112 respectively. The time during which the plasma concentration remained above the MIC ( $\triangle \mathrm{T} / \mathrm{MIC})$ was $1132.93 \mathrm{~h}$.

Experimental murine foreign-body peritonitis. 
117 In the experimental model, the mortality in control groups was 80\% (table 1). In imipenem118 treated groups the mortality was reduced to $0 \%$ and $6 \%$ for SL and S implants, respectively $(\mathrm{p}<0.01)$. No 119 difference in mortality was observed among treated groups.

A significant decrease in bacterial counts obtained from livers, spleens and catheters was observed 121 in the imipenem-treated groups compared to control groups $(\mathrm{p}<0.01)$. Moreover, catheter clearance was 122 greater in the imipenem $\mathrm{S}$ compared to the imipenem SL treated group $(\mathrm{p}=0.021)$.

The percentage of positive blood cultures in the treated groups was lower than that of the controls $(\mathrm{p}<0.01)$, without differences between treated groups. However, there were no significant 125 differences in the percentage of postive cultures of peritoneal washings between control and treated 126 groups.

Our results show differences in the clearance of bacteria between SL and S catheter groups treated with imipenem. The lower clearance obtained in the catheter culture from the infected animals carrying SL catheters could be related to the loss of OprD2 induced by zinc, as has been demonstrated in vitro [5]. However, there were no differences in the bacterial counts in the liver and the spleen, as well as in the percentage of positive blood cultures, which suggests that this might be a local rather than a systemic effect.

The clinical implications of these results are difficult to ascertain. Zn eluted from siliconized

134 latex favours the survival of P. aeruginosa at a local level. Whether or not this local phenomenon has an 135 effect on the prognosis of these infections in clinical practice remains to be demonstrated [6, 7]. However, 136 these data suggest that latex urinary catheters should not be used in humans. In our opinion, latex urinary 137 catheter should be changed to other materials that are more biocompatible, such as silicone. In fact, this 138 change has already been made in many hospitals [7]. However, siliconized latex urinary catheters are still 139 used in many countries because they are very cheap.

140 In summary, imipenem activity against $P$. aeruginosa might locally decrease in to the presence 141 of siliconized latex devices, with this effect probably due to the zinc eluted from the biomaterial. 


\section{Acknowledgements}

144

145 This work was supported by the Dirección General de Investigación del Ministerio de Ciencia y

146 Tecnología, Spain (project SAF2003-01241) and by Ministerio de Ciencia e Innovación, Instituto de 147 Salud Carlos III - co-financed by European Development Regional Fund "A way to achieve Europe"

148 ERDF, Spanish Network for the Research in Infectious Diseases (REIPI RD06/0008).

149 There are no conflicts of interest regarding this work.

150 
1. Martínez-Martínez L, Pascual A, Conejo MC, Picabea L, Perea EJ. (1999) Resistance of Pseudomonas aeruginosa to imipenem induced by eluates from siliconized latex urinary catheters is related to outer membrane protein alterations. Antimicrob. Agents Chemother; 43:397-399.

2. Conejo MC, Martinez-Martinez L, Garcia I, Picabea L, Pascual (2003) A. Effect of siliconized latex urinary catheters on the activity of carbapenems against Pseudomonas aeruginosa strains with defined mutations in $\operatorname{ampC}$, oprD, and genes coding for efflux systems. Int. J. Antimicrob. Agents; 22: 122-127.

3. Espersen, F, Fridmodt-Moller N (1999). Murine model of peritonitis involving a foreign body. In: O. Zak, and M. A. Sande, eds. Handbook of animal models of infection. Academics Press. London, United Kingdom;183-188

4. Perron K, Caille O, Rossier C, Van Delden C, Dumas JL, Kohler T (2004). CzcR-CzcS, a two component system involved in heavy metal and carbapenem resistance in Pseudomonas aeruginosa. J. Biol. Chem; 279: 8761-8768.

5. Conejo MC, Garcia I, Martinez-Martinez L, Picabea L, Pascual A (2003). Zinc eluted from siliconized latex urinary catheters decreases OprD expression, causing carbapenem resistance in Pseudomonas aeruginosa. Antimicrob. Agents Chemother; 47: 2313-2315.

6. Hernández-Burruezo JJ, Omar Mohamed-Balghata M, Aliaga Martínez L and Sociedad Andaluza de Enfermedades Infecciosas (SAEI) (2007). [Urinary tract infections]. Med Clin (Barc); 129:707-15.

7. Hooton TM, Bradley S F, Cardenas D D, Colgan R, Geerlings SE, Rice JC, et al. (2010). Diagnosis, Prevention, and Treatment of Catheter-Associated Urinary Tract Infection in Adults: 2009 International Clinical Practice Guidelines from the Infectious Diseases Society of America. Clin Infect Dis 50:625-663. 
Table 1: Effect of imipenem therapy on the clearance of Pseudomonas aeruginosa PAO1 from catheter, liver, spleen, blood and peritoneal fluid from mice implanted 10 11180

12

15
16

17
18

19

20

21

$2 2 \longdiv { 8 1 }$

2318

25183

26184

27184

28185

29

30

31

32

33

34

35

36

37

39

40

42

43

45

46

\begin{tabular}{|c|c|c|c|c|c|c|c|}
\hline Catheter/treatment & $\begin{array}{c}\text { Inoculum } \\
\text { Log CFU/ml }\end{array}$ & $\begin{array}{c}\text { Liver } \\
\text { Log CFU/g }\end{array}$ & $\begin{array}{c}\text { Spleen } \\
\text { Log CFU/g }\end{array}$ & $\begin{array}{c}\text { Catheter } \\
\text { Log CFU/ml }\end{array}$ & $\begin{array}{c}\text { Percentage of positive } \\
\text { blood culture }\end{array}$ & $\begin{array}{l}\text { Percentage of positive } \\
\text { peritoneal washing Culture }\end{array}$ & Exitus \\
\hline L Control & $6.98 \pm 0.23$ & $8.24 \pm 1.21$ & $8.23 \pm 1.61$ & $6.90 \pm 0.87$ & $100 \%$ & $100 \%$ & $80 \%$ \\
\hline Control & $6.98 \pm 0.23$ & $8.52 \pm 0.88$ & $8.24 \pm 1.63$ & $7.33 \pm 0.46$ & $100 \%$ & $100 \%$ & $80 \%$ \\
\hline L imipenem & $6.89 \pm 0.35$ & $3.04 \pm 0.80 *$ & $4.01 \pm 0.91 *$ & $3.82 \pm 2.02 *$ & $57.1 \% *$ & $100 \%$ & $0 \% *$ \\
\hline imipenem & $6.98 \pm 0.23$ & $3.11 \pm 1.03 *$ & $4.06 \pm 1.04 *$ & $2.27 \pm 1.71 * \#$ & $53.3 \% *$ & $93.3 \%$ & $6 \% *$ \\
\hline
\end{tabular}

$* \mathrm{p}<0.01$ with respect to SL Control and S Control; \#p=0.021 with respect to SL imipenem. 